\title{
POSTMORTEM HAZARD OF MYCOBACTERIUM TUBERCULOSIS
}

Dr. Swayam Jothi S, Professor \& Head,

\author{
Department of Anatomy, Shri Sathya Sai Medical College \& Research Institute, \\ Sri Balaji Vidyapeeth, Nellikuppam, Kancheepuram Dist., Tamil Nadu - 603 108, India.
}

?

Tubercular decay has been found in the spines of Egyptian mummies in the British Museum. Tuberculosis has been present in humans since antiquity. The earliest unambiguous detection of $M$. tuberculosis involves evidence of the disease in the remains of bison in Wyoming dated to around 17,000 years ago. Cadavers are the main studying material of Anatomists. ${ }^{1}$ Mycobacterium tuberculosis, hepatitis B and $\mathrm{C}$, the AIDS virus HIV and prions are the infectious pathogens of risk for those who handle the dead bodies during embalming procedures and dissection of cadavers. Tuberculosis affects not only lungs but many of the organs of the body.The organism is an acid fast bacillus. The risk of acquiring tuberculosis varies according to occupation and Anatomy department workers are at particular risk of contracting tuberculosis carried by cadavers ${ }^{2-4}$ Embalming cases known to be infectious with $M$.tuberculosis, hepatitis $\mathrm{B}$ and C. HIV and prions should be avoided. Every cadaver should be regarded as an infectious material.

But if the bodies are to be embalmed for a short duration or for transportation, the task is undertaken. When the cause of death is not known, people involved are at risk for the following reasons. First, in suspension tests, the cell-free infectious agent is tested, whereas in humans,some infective agents can localize within cells. Second, the concentration of the embalming fluid components decreases as they diffuse throughout the human body.Third, several classes of products, including formalin,alcohols and phenolic agents are partially inactivated by the presence of protein. This sensitivity to organic load suggests that the efficiency of the disinfectants will be much lower in cadavers than in vitro tests. ${ }^{5}$ Fourth, although a certain fixatives at certain levels may be cidal to a single agent or even a group or class of infectious agents, other agents that co exist may survive as mentioned above thus complete disinfection may not be accomplished. This being the situation an attempt was made by taking up a small project work on 28 cadavers with 84 samples of body fluids from them for Gram's and AFB staining techniques. All were negative. ${ }^{6}$ However,the following precautions have to be followed.

Universal precaution while embalming.

Vaccination is must for all who handle cadavers against Hepatitis B and M. tuberculosis ${ }^{7}$

One must update their knowledge in this field to help ensure the safety of all educators, researchers, and students under their charge.

\section{REFERENCES:}

1. Aziz MA, Mckenzie JC, Wilson JS ,Cowie RJ,Ayeni SA, Dunn BK. 2002. The human cadaver in the age of biomedical informatics. Anat Rec (New Anat) 269:20-32.

2. Smith GS. 1953 Tuberculosis as a necropsy room hazard. J Clin Pathol $6: 132-134$.

3. Sterling TR, Brehm WT, Moore RD, Chaisson RE.1999. Tuberculosis vaccination versus isoniazid preventive therapy: A decision analysis to determine the preferred strategy of tuberculosis prevention in HIV-infected adults in the developing world. Int J Tuberc Lung Dis 3:248-254.

4. Kappel TJ, Reinartz JJ, Schmid JL, Holter JJ Azar MM. 1996. The Viability of Mycobacterium tuberculosis in formalin fixed autopsy tissue; Review of literature and brief report. Hum Pathol 27:1361-1364.

5. De Craemer D. 1994, Postmortem viability of human immunodeficiency virus implications for teaching of anatomy. N Eng J Med 331:1315.

6. Karthika Jayakumar, Swayam Jothi: 2012. Safety in Handling of cadavers International journal of Medical and Clinical Research Vol: 3,Issue 3,2012,pp140-142.

7. Sterling TR.Pope DS, Bishai WR, Harrington S, Gershon RR, Chaissson RE. 2000. Transmission of Mycobacterium tuberculosis from a cadaver to an embalmer. N Engl J Med 342:246-248. 